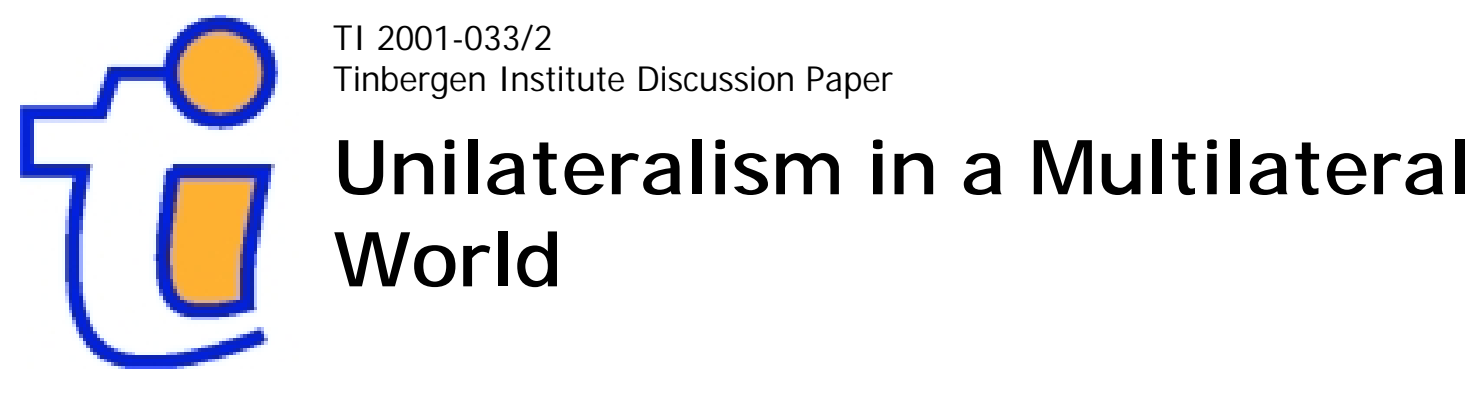

Wilfred J. Ethier 
Tinbergen Institute

The Tinbergen Institute is the institute for economic research of the Erasmus Universiteit Rotterdam, Universiteit van Amsterdam and

Vrije Universiteit Amsterdam.

Tinbergen I nstitute Amsterdam

Keizersgracht 482

1017 EG Amsterdam

The Netherlands

Tel.: +31.(0)20.5513500

Fax: $\quad+31 .(0) 20.5513555$

Tinbergen Institute Rotterdam

Burg. Oudlaan 50

3062 PA Rotterdam

The Netherlands

Tel.: $\quad+31 .(0) 10.4088900$

Fax: $\quad+31 .(0) 10.4089031$

Most TI discussion papers can be downloaded at

http://www.tinbergen.nl 


\section{UNILATERALISM IN A}

MULTILATERAL

WORLD

Wilfred J. Ethier

Department of Economics

University of Pennsylvania

First version: April 21, 1997

This printing: March 14, 2001 


\title{
UNILATERALISM IN A MULTILATERAL WORLD
}

\author{
Wilfred J. Ethier
}

Department of Economics

University of Pennsylvania

Philadelphia, PA 19104-6297 telephone: (215) 898-5105

fax: (215) 573-4217

e-mail: ethier@econ.sas.upenn.edu

Abstract: This paper addresses the interplay between unilateralism and multilateralism. I first describe their respective stylized facts. I next present a simple, multi-country model with high initial tariff barriers and with the features that have always been of paramount concern to policymakers, allow governments to negotiate multilateral agreements, and analyze the resulting equilibrium. I then consider the possibility of unilateralism and find a role for a system with features remarkably similar to contemporary unilateralism. The relationships between multilateralism and unilateralism are subtle: Unilateralism has the properties it has because the world is multilateral (the insurance triangle); to be useful unilateralism requires a multilateral component of some type; this type results from a basic compatibility problem between those who negotiate multilaterally and those who establish unilateralism.

Keywords: Unilateralism, multilateralism, administered protection, insurance triangle, multilateral component, compatibility problem.

\section{JEL Classification Codes: F02, F13}

\section{Contents:}

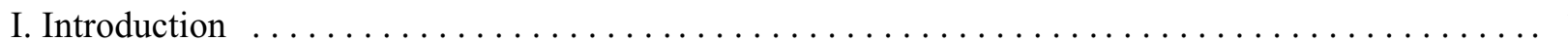

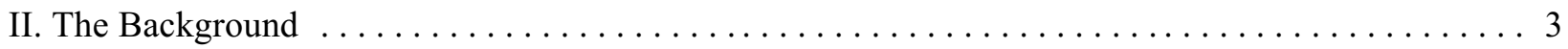

The stylized facts of multilateralism (3)

The stylized facts of unilateralism (4)

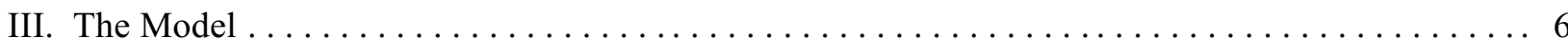

The constituents (6)

Negotiators' objectives (7)

Sequence of moves within each period (7)

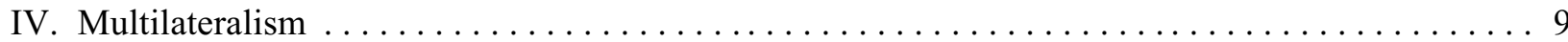

Multilateral negotiations (9)

Negotiated multilateral liberalization (10) 
The allocation of resources (12)

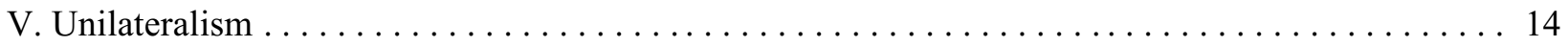

The potential for unilateralism (15)

A model of unilateralism (16)

The followers (18)

The unrestrained leaders (19)

The restrained leaders (20)

The laggards (23)

The effect of unilateralism on resource allocation (25)

The insurance triangle (26)

The split personality (27)

The compatibility problem (29)

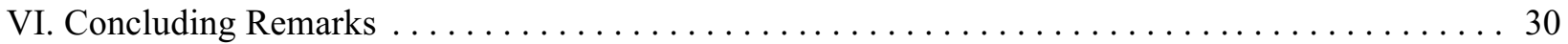

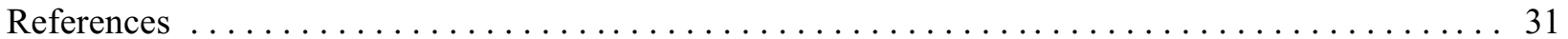

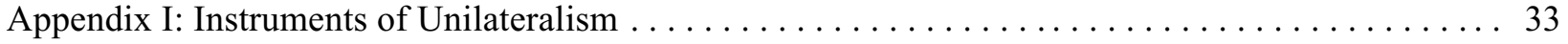

The instruments (33)

Changing instrument use (34)

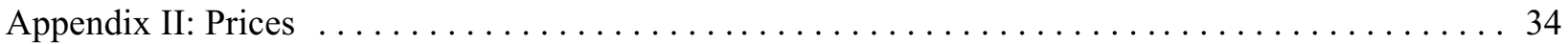

Relative commodity prices (34)

Real rewards (35) 


\title{
UNILATERALISM IN A MULTILATERAL WORLD
}

\author{
Wilfred J. Ethier* \\ University of Pennsylvania
}

INTERNATIONAL TRADE POLICY has a split personality. As the nations of the world have gradually and collectively adopted historically low levels of protection for more than half a century, they have gradually and individually initiated protectionist actions at an increasing pace. What's going on here?

\section{Introduction}

Contemporary international trade policy is built upon two pillars: multilateralism (the rounds of multilateral trade negotiations sponsored by the General Agreement on Tariffs and Trade [GATT] and the multilateral World Trade Organization [WTO]); unilateralism (rules - explicit and implicit - for national governments to respond to political pressures for protection). ${ }^{1}$ This paper concerns the relationship between these two components and the nature of the system they jointly determine. I shall argue that neither can be properly

\footnotetext{
"I gratefully acknowledge useful comments from Arye Hillman, Henrik Horn, and Rodney Ludema, from referees of this Journal, and from helpful discussions during presentations of this research at EPRU in Copenhagen, the Institute of World Economics in Kiel, the ISER at Osaka University; the RIEB at Kobe University; Doshisha, Keio, Konstanz, Southern Methodist, Texas A\&M, Tohoku, and Tokyo Universities; the Universities of Helsinki, Maryland, New Orleans, Paris I, Texas, and Wisconsin; the 1999 North American Summer Meetings of the Econometric Society.

${ }^{1}$ A third pillar-regionalism - has been resurrected during the past decade, but I shall ignore this below because I have discussed it at length elsewhere: Ethier (1998a, c). See Ethier (1998b) for a discussion of why multilateralism is what it is, Ethier (2001) for an overview of multilateralism and unilateralism, and Ethier (1998d) for an overview of the relation between unilateralism, multilateralism, and regionalism.
} 
understood in isolation, and that familiar tools of trade policy appear in a dramatically different light when the two are treated together.

My analysis will be positive, but conclusions will have normative applications. In particular, I shall address the following basic questions: How do the two components, and their interactions, determine the pace of trade liberalization? Why does unilateralism take the very special form that it does?

In what follows I first describe the stylized facts of multilateralism and unilateralism. I next present a multi-country model with high initial tariff barriers. These initial barriers would not have been chosen by the policymakers in the model subsequently presented. Rather, the barriers are assumed to be a legacy of an earlier, different, regime (just as, in the decades since World War II the world has had to deal with the protection resulting from the radically different inter-war years), but the existence of these barriers produces special interests that resist their removal. Governments negotiate successive tariff reductions in a sequence of periods - a caricature of the GATT negotiating rounds of the last 5-6 decades.

My model is very special but not arbitrary: I attempt to find the simplest structure consistent with the two concerns that have dominated tariff negotiations for centuries. These are: $\mathbf{1}$ dealing with special interests that desire protection; $\mathbf{2}$ giving negotiators insurance should the ex post environment turn out significantly different from what they expected when they made the agreements. This is achieved by the assumed sequence of moves within each period.

First, forward-looking labor allocates itself between the export and import-competing sectors, remaining for the rest of the period specific to the sector it has chosen. Next, governments negotiate tariff reductions. After this, a technology shock occurs. Then trade takes place, with the new technology and constrained by the negotiated tariffs. Because negotiations occur when labor is sector specific there are special interests; because the negotiations occur before the technology draw the governments do not then know to what environment the results of those negotiations will apply.

I describe a process of multilateral negotiation resulting in steady liberalization at a moderate rate. I next investigate the possible role of a system of rules allowing countries, whose import-competing sectors face competition from exports from countries with a favorable technology draw, to impose temporary protection. If such protection also benefits those countries whose exporters must compete with the countries with a favorable technology draw while being acceptable to the latter (the "insurance triangle"), it can accelerate the rate of liberalization and increase the allocation of resources to comparative-advantage sectors. But a time-consistency problem compounded by an externality ensures that negotiators would never themselves adopt such rules for their respective countries: The "split personality" of trade policy is essential. In short, features remarkably similar to contemporary unilateralism turn out to be crucial, with subtle and essential relationships to multilateralism, that cannot be understood in a two-country context. 


\section{The Background}

This section briefly describes the essential features of multilateralism and of unilateralism motivating the subsequent model.

\section{The stylized facts of multilateralism}

I mean the entire GATT-WTO structure, but shall distill it into six stylized facts.

- Tariffs are the instruments of protection.

- The countries of the world multilaterally negotiate tariff reductions.

- The negotiated liberalization is gradual.

Negotiated agreements feature reciprocity: the mutual exchange of concessions.

- Nondiscrimination characterizes trading relations: Each country is a Most Favored Nation (MFN) of every other country. ${ }^{2}$

- Punishments for alleged violations of past agreements have consistently been commensurate with the violation, that is, tit-for-tat.

Reducing multilateralism to these stylized facts is deficient in one way. Multilateral liberalization has increasingly shifted from the further reduction of already reduced tariffs to broadening liberalization into additional areas, notably agriculture, services, and intellectual property. Attention has necessarily shifted to government policies other than tariffs.

Consideration of these would not alter the following argument, so I abstract from them and pretend that continued multilateral liberalization is only the continued reduction of tariffs.

In an earlier paper (Ethier 1998b) I used a model like that which follows to show how, with initial high protection consisting only of tariffs, most of the other stylized facts - multilateral negotiations, gradual liberalization, reciprocity, and MFN — will develop endogenously, if government behavior is dictated by a political support function consistent

\footnotetext{
${ }^{2}$ One country extends MFN status to another if the former agrees that goods from the latter will never face a duty higher than the duty applied to similar goods from any other country. In practice this raises the issue of defining "similar goods," but I shall abstract from such problems.
} 
with how governments claim to behave, and if reasonable substitutes for each country's exports are produced elsewhere. Therefore in this paper I shall simply take the stylized facts of multilateralism as given. Other authors have also discussed why multilateralism has the properties it has (see Staiger (1995) for a discussion of earlier contributions); the recent papers that come closest to addressing these same properties are Bagwell and Staiger (1999a,b).

\section{The stylized facts of unilateralism}

Unilateralism consists of rules for intervention rather than tariff rates, and both the nature of the rules and the way they are used have been changing over time. The more important rules, and the changing use, are described in Appendix I. Here I identify five stylized facts that characterize - more or less - a common denominator for the rules of unilateralism. ${ }^{3}$

\section{- Exporters are COMPENSATED, at least in part.}

Rents generated by voluntary export restraints (VERs) accrue to the exporters, who administer the quotas. Usually the exporting firms themselves capture the rents. Safeguards explicitly require that exporters be compensated, but the compensation is to the exporting country rather than the exporting firms.

Antidumping and countervailing duties are ostensibly tariffs, but a closer look at how these instruments are actually used reveals that they also confer significant compensation.

Roughly one third of US antidumping petitions result in duties, about one third are rejected, and the others are withdrawn. Of these, many are withdrawn after a settlement between domestic and foreign firms. Typically the foreign firms collectively undertake to raise prices or restrict exports. Prusa (1992) reports that withdrawn petitions restrict trade almost as much, on average, as petitions resulting in duties, implying that negotiated settlements are, on average, more restrictive than antidumping duties.

If, instead, a petition does produce an antidumping duty, the result is usually higher export prices, not tariff revenue. Tariffs collected are often rebated when authorities determine, ex post, that the goods were not in fact dumped. ${ }^{4}$ The exporter, realizing that the price in the importing country is going to rise by the dumping margin no matter what he or she does, raises the export price by that amount. The purpose of an antidumping law is not to

\footnotetext{
${ }^{3}$ See also Hillman $(1982,1990)$

${ }^{4}$ But, in the US at least, the importer will incur additional liability if it is determined that the goods were in fact dumped by more than the duty. This implies that it is riskier to buy goods from a country against which there is an outstanding dumping determination than from some other source at the same price.
} 
impose temporarily a conventional tariff; it's to force exporters to raise prices. Just as with VERs, the exporters usually get the rents. ${ }^{5}$

I do not claim that unilateralism benefits foreign firms, or that it leaves them more or less indifferent. This is possible. But the first stylized fact of unilateralism is just that countries denied market access receive significant - if only partial_compensation.

It is curious that governments should want to, in effect, hand over tariff revenue to foreigners. But this is exactly what they do, routinely, in the conduct of unilateralism. Why? I shall argue that unilateralism is what it is because of successful multilateralism.

\section{- The instruments provide TEMPORARY (at least in original intent) protection.}

Temporary measures are not necessarily short-lived: they can be renewed. Renewals allow for adjustments and so add flexibility (relative to measures that require congressional action and/or multilateral negotiation).

\section{- The restrictions are DISCRIMINATORY.}

Some industries have displayed a comprehensive web of voluntary export restraints (e.g., textiles and apparel). But individual VERs are bilateral and thus inherently discriminatory.

Antidumping and countervailing duty laws are WTO-consistent, but discriminatory, since they apply to the products of specific countries. Safeguards, alone are nondiscriminatory. So it is significant that their use has greatly declined relative to that of the other three instruments and that in the future it will sometimes be permissible to employ them in a discriminatory manner.

\section{- TARIFF-QUOTA EQUIVALENCE is high.}

The proposition of tariff-quota equivalence asserts that any equilibrium that can be supported by a tariff policy can also be supported by an appropriate quota policy, and vice-versa. But tariffs and quotas are seldom equivalent in fact. If an equilibrium is disturbed, the response depends on whether a tariff or a quota is in place, so if a policy must be implemented before all circumstances are known, it matters what tool is used. But unilateralism is one theater where tariff-quota equivalence is really relevant: Each instrument seeks to attain a particular outcome with a restriction that can be readjusted frequently. So it matters little whether the restriction is quantitative or not.

\footnotetext{
${ }^{5}$ Usually, but not always. Sometimes the duty is large enough to reduce imports drastically, or to eliminate them altogether, so that the higher price is little consolation to exporters. Sometimes (particularly in Europe) administration hinders the ability of the exporter to capture the price rise. And countries not in the WTO may apply the label "antidumping law" to any sort of protectionist measure.
} 
- The restrictions are designed by officials DISTINCT FROM THOSE WHO NEGOTIATE international trade agreements.

This applies to some degree to most industrial countries, but most dramatically to the U.S. For over 60 years the Congress has repeatedly ceded to the executive considerable authority to set actual tariff levels via reciprocal trade negotiations, and throughout this period the executive has consistently been less protectionist than Congress. Yet, at the same time, Congress has repeatedly revised the laws governing administered protection to limit executive discretion and to make protection a more likely response to petitions for relief.

\section{The Model}

I now describe a simple formal model of successive multilateralism. I will then inquire into the possibility of a role for unilateralism. I construct the model to reflect those features of the world that in fact have been of the most concern to policymakers. Since this is necessarily subjective to at least some degree, I shall from time to time pause to defend a modeling choice.

\section{The con stituents}

Assume two goods, $A$ and $B$, one factor of production, labor $(L)$, and $2 N$ identical (almost) countries. Normalize $L=1$ for each country. Everyone spends equally on the two goods. $N$ countries have a comparative advantage in $A$ and $N$ in $B$. Labor productivity is $\alpha a$ in the comparative-advantage good and $a$ in the other good, with $\alpha>1$. I will examine symmetric equilibria in which each country makes the same allocation, $\ell$, to the comparative advantage sector.

Assume a succession of periods. Labor is mobile between sectors across periods, but immobile within each period. Initially, each country starts with a common, historically given, tariff $t$ on all imports and an initial state, $a$, of technology. The state of the world each period is indicated by $(t, a)$, since $t$ and $a$ will remain common to all countries across the symmetric equilibria I consider. At the start of each period, countries differ from each other only in regard to which sector possesses a comparative advantage.

Technology is improving across periods. Since my topic is trade policy rather than growth, I am content to assume that this occurs at an exogenously determined rate, that is, 
$\Delta a / a=\beta-1>0$. Technical progress, regardless of where it originates, spills over - subject to a qualification introduced below - to all countries: It constitutes an international externality.

\section{Negotiators' objectives}

Governments may negotiate tariff reductions. I want an objective function accurately reflecting how government negotiators behave; I build on Corden's (1997, pp 74-76) description of a conservative social welfare function: Governments avoid policies that would seriously harm any interest group. In particular, I assume that, in each period, each government's negotiators want to maximize:

$$
\phi(\tau)=\Delta r_{s}(\tau)-\left(-\Delta r_{m}(\tau)\right)^{1+\gamma}
$$

where $\tau$ denotes the rate of tariff reduction $\left(-\frac{t}{1} / 1+t\right), \Delta r_{X}$ the negotiators' perception of the increase in the real reward of the factor specific to exports, and $\Delta r_{M}$ the negotiators' perception of the increase in the real reward of the factor specific to imports. ${ }^{6}$

Appendix II shows that liberalization will cause $\Delta r_{x}>0$ and $\Delta r_{m}<0$, with a positive gain overall. So liberalization will be desirable if either $\gamma$ or the degree of liberalization is modest enough. The parameter $\gamma$ measures the negotiators' averseness to allowing anyone to suffer a large loss: the Corden sensitivity.

\section{Sequence of moves within each period}

At the start of each period, the common tariff and technology, $(t, a)$, is inherited from the close of the previous period. The following sequence then takes place.

First, $L$ allocates itself among $A$ and $B$. The allocations become specific for the rest of the period, so each worker decides which sector to enter based on his/her rational forecast of the real rewards that will be offered in the respective sectors during the current period.

Second, the governments negotiate tariff reductions. These negotiations will be multilateral and feature nondiscrimination. I assume that each govemment, like the owners of $L$, does not look beyond the current period, but is forward-looking within that period.

Third, some countries succeed in anticipating the technological improvement that will be generally realized at the end of the period: $n<N$ of the exporters of one of the goods will

\footnotetext{
${ }^{6}$ The results that follow would not be qualitatively affected if the objective function were over real incomes instead of over real rewards.
} 
now have the large technology gain, $\Delta a / a=\beta-1$, for their exportables. The identities of the good and of the specific exporters of that good that will succeed in anticipating the technological improvement is determined by a random draw (so, if $\pi \equiv n / N$, then $\pi / 2=$ the probability of early technical progress for each country). N.B.: The identity of the gainers (both which good and which countries) is determined after the negotiations.

Fourth, tariff reductions are implemented and trade is realized. The latter will be described subsequently. In each country, tariff revenue is distributed to the populace in lump-sum fashion.

Finally, the period ends, $\Delta a$ is realized by all countries and both sectors for the next period, and the negotiated $t$ becomes the initial $t$ for the next period, when new governments will again determine policy.

I intend a period to correspond, in some rough fashion, to the time between the start of one GATT round and the start of the next. I've tried to build the simplest model I can that captures the two features that have always been paramount to those undertaking trade negotiations: 1 the existence of divergent special interests; $\mathbf{2}$ concern that any agreement might have unforeseen and unfavorable future consequences. This is achieved by my description of within-period timing, which will be crucial to what follows. The assumption that factors are specific when negotiations takes place produces the divergent interests.

The assumption that negotiations are conducted before the economic environment to which their results will apply is fully known serves to introduce the second paramount feature. ${ }^{7}$ This point has, in fact, always been (since long before the GATT) of acute concern to policymakers. Trade agreements routinely included safeguards (then known as escape clauses) enabling participants to readjust their concessions should events not turn out as they had hoped. When the US first established safeguards as a matter of law, material injury had to be due to increased imports and the latter had to be due to a prior trade concession. The GATT itself provided, in Article XXVIII, opportunities for the modification or withdrawal of concessions.

Introducing additional instruments could neutralize both features. Lump-sum transfers would deal with the first, and the ability to implement fully state-contingent trade agreements would do it for the latter. The absence of both instruments from my model does no violence to its realism.

${ }^{7}$ For example, participants in prior GATT rounds had not known that Japanese automobile firms would become the most efficient producers in the late 1970s. 


\section{Multilateralism}

Labor allocates itself across sectors on the basis of a rational forecast of the rate of liberalization that governments will subsequently negotiate, and when those negotiations take place the allocation of labor is given. I first investigate what rate of liberalization will be negotiated for a given allocation $\ell$, and then go backwards to investigate what labor, armed with an understanding of this relation between $\ell$ and liberalization, will actually do.

\section{Multilateral negotiations}

What rate of tariff reduction will be negotiated? At the negotiations, governments know the allocation of resources, but they do not know which countries will be the leaders, the followers, and the laggards when the negotiated tariff reductions are implemented. I assume no external commitment mechanism: A government will actually implement the reduction it has agreed to only if, ex post, that government believes its interests will be served by doing so, taking into account credible threats of retaliation.

I assume the retaliation is tit-for-tat. That is, if Country 1 lowers its tariff $5 \%$ less than promised, its trading partners follow suit. Why tit-for-tat? The sixth stylized fact of multilateralism (punishments for alleged violations of past agreements have consistently been commensurate with the violation, that is, tit-for-tat) gives me little choice. When countries retaliate or threaten to retaliate against some alleged transgression by a trading partner, they consistently emphasize that the threatened retaliation is commensurate with the transgression (i.e., tit-for-tat). The WTO and the GATT before it have consistently operated on the premise that punishment should match violation. Countries have often squabbled over which tit matches what tat, or whether there was a tat in the first place, but as far as I know no country has ever challenged the principle. Given my goal of modeling countries as they actually behave, this makes the tit-for-tat assumption compelling. ${ }^{8}$

Note also that tit-for-tat punishment fits neatly into the present model. With the symmetric equilibria that I consider, such a threat will be well-defined.

Furthermore, the use of tit-for-tat in my model implies government behavior very much in the spirit of the Corden political support function I use. To see this, note that such a threat can support any negotiated tariff reduction which, ex post, every country wants to have generally adopted. But it can support no reduction in excess of what any country regards, ex post, as optimal. Thus the outcome of the multilateral negotiation will be: the smallest of the

\footnotetext{
${ }^{8}$ Adding a lag between deviation and retaliation would complicate the following algebra without affecting the essentials of the argument.
} 
various tariff reductions which, if generally adopted, would maximize ex post the objective functions of the respective negotiating governments. That is, no government negotiator will be taking the risk that its import competing sector might have to take a bigger hit than that negotiator would have been willing to allow.

\section{Negotiated multilateral liberalization}

Let $P_{i}$ and $Q_{i}$ respectively denote international and domestic relative prices of $B$ in terms of $A$, when the technical advance occurs first in $\operatorname{good} i, i=A, B$. An asterisk distinguishes the country with a comparative advantage in $B$. Then, with $t$ common to all countries,

$$
Q_{i}=P_{i}(1+t), 1 / Q_{i}^{*}=(1+t) / P_{i}
$$

We have, recalling that $\ell$ denotes the labor allocated to the comparative-advantage sector, (see Appendix II for details),

$$
P_{A}(\ell, t)=\pi[\beta-1] \frac{\alpha \ell}{\alpha \ell+(1+t)(1-\ell)}+1
$$

if $A$ is the leader, and $P_{i}=P_{B}=1 / P_{A}$ if $B$ is the leader. Then $P_{A}>1>P_{B}$.

The hypothesized spending pattern is consistent with the following indirect utility function:

$$
v=Q^{-1 / 1} I
$$

where $I$ denotes income in terms of good $A$. Factors are paid the values of their marginal products, so that their real rewards, using the utility function (2), are as follows, for a country with a comparative advantage in $A$ :

$$
\begin{array}{ll}
r_{x}^{L}=\frac{\beta \alpha a}{Q_{A}^{1 / 2}} \quad r_{x}^{F}=\frac{\alpha a}{Q_{A}^{1 / 2}} \quad r_{x}^{G}=\frac{\alpha a}{Q_{B}^{1 / 2}} \\
r_{\Delta}^{L}=a Q_{A}^{1 / 2} \quad r_{\Delta}^{r}=a Q_{A}^{1 / 2} \quad r_{\Delta}^{\sigma}=a Q_{s}^{1 / 2}
\end{array}
$$


Let $\tau^{i}=\left(\frac{-\dot{t}_{i}}{1+t}\right)$ denote the rate of tariff reduction optimal ex post for a country that ends

up in state $i=L, F$, or $G$. For simplicity I consider a continuous-time approximation to the negotiated rate of tariff reduction. Then, the ex post value of each country's objective function reduces to

$$
\phi(\tau)=-\frac{d_{x}^{i}}{d t}(\tau)-\left(\frac{d d_{m t}^{i}}{d t}(\tau)\right)^{1+\gamma}
$$

where $i$ denotes the state the country finds itself in ex post. If $\gamma=0, \phi$ can be made arbitrarily large by making $\tau$ arbitrarily large: The government will want free trade at once. I will accordingly refer to the Corden sensitivity $\gamma$, which reflects the government's reluctance to let any sector experience a large hit, as the willingness to protect.

$$
\text { Now, } \frac{d r_{s}{ }^{1}}{d t}=-\frac{\beta \alpha a}{2 P_{A}^{1 / 2}}(1+t)^{-3 / 2}=-\frac{r_{s}{ }^{2}}{2(1+t)} \text { and } \frac{d r_{m}^{L}}{d t}=\frac{a}{2}(1+t)^{-1 / 2} P_{A}^{1 / 2}=\frac{r_{m}^{L}}{2(1+t)} \text {, etc. The }
$$

first-order condition that $\tau$ maximize the objective function, given the value of $P_{i}$, reduces to

$$
\left(\tau^{i}\right)^{\gamma}=\frac{-\left(d r_{x}^{i} / d t\right)}{(1+\gamma)\left(d r_{m}^{i} / d t\right)^{1+\gamma}(1+t)^{\gamma}}
$$

where $i=L, F$, or $G$. Substituting yields

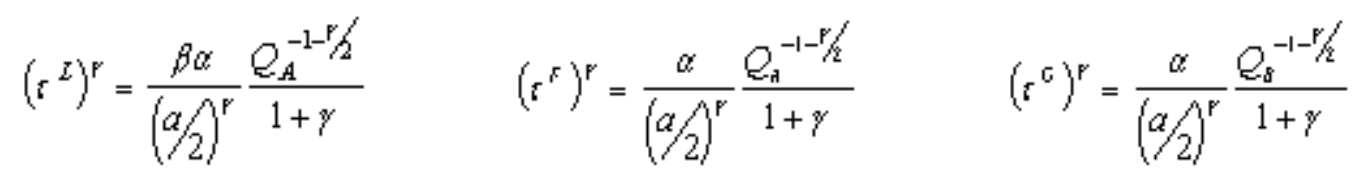

Since $\beta>1, \tau^{L}>\tau^{F}$, and $Q_{A}>Q_{B}$ implies that $\tau^{G}>\tau^{F}$. Intuitively, leaders prefer a relatively liberal regime because of their technological advantage. Laggards take a hit in their importcompeting sector, but this is ameliorated by a more favorable terms of trade. Followers, competing with the advantaged leaders in export markets, take the hit in their export sectors, with no terms of trade improvement.

Proposition 1 The multilaterally negotiated rate of tariff reduction, $\tau^{M}$, equals the rate most preferred, ex post, by those countries that turn out to be the followers: 


$$
\tau^{N}=\left(\frac{a}{(a / 2)^{r}} \frac{1}{1+\gamma}\right)^{\frac{1}{r}}\left(\frac{1}{P_{\mathrm{N}}(1+t)}\right)^{\frac{1}{P}+\frac{1}{2}} .
$$

Proposition 1 in turn implies $\partial \tau^{M} / \partial \gamma<0, \partial \tau^{M} / \partial \ell>0$, and $\partial \tau^{M} / \partial t<0$. Thus,

Proposition 2 A greater willingness to protect implies a smaller rate of tariff reduction, and the rate of tariff reduction accelerates over successive rounds.

\section{The allocation of resources}

Consider next where labor, understanding the above negotiating process, will have chosen to locate. Let $r_{i}, i=x, m$, denote the expected quasi-rent of labor specific to sector $i$, where $x$ refers to the sector in which a country has a comparative advantage. Then

$$
r_{i}=\frac{\pi}{2} r_{i}^{L}+\frac{1-\pi}{2} r_{i}^{F}+\frac{1}{2} r_{i}^{G}
$$

where $r_{i}^{L}, r_{i}^{F}$, and $r_{i}^{G}$ respectively denote the rent when the country is a technological Leader, has a comparative advantage in the leading good but is not itself a leader (i.e., is a Follower), and has a comparative advantage in the laGgard good. ${ }^{9}$

The ex post real quasi-rents (3) and (4) imply the expected returns to the quasi-specific factors, net of tariff revenue:

$$
\begin{gathered}
r_{x}\left(P_{A}, t\right)=\frac{\alpha a}{2(1+t)^{1 / 2}}\left\{\frac{\pi[\beta-1]+1}{P_{A}^{1 / 2}}+P_{A}^{1 / 2}\right\} \\
\gamma_{m}\left(P_{A}, t\right)=\frac{a}{2}(1+t)^{1 / 2}\left\{\frac{1}{P_{A}^{1 / 2}}+P_{A}^{1 / 2}\right\} .
\end{gathered}
$$

${ }^{9}$ For example, in the early 1980s, the Japanese automobile firms, having developed "lean" production metho ds, were the leaders, the high-cost European and fledgling Korean firms the followers, and the import-competing US firms the laggards. 
Here $t$ has the value that labor expects to pertain after the subsequent negotiations: $t=t_{1}-\tau^{M}\left(1+t_{1}\right)$, where $t_{1}$ denotes the tariff inherited from the previous period. Assume that labor allocates itself between sectors according to the relative expected quasi-rents. Note that $r_{x}\left(P_{A}, 0\right)>r_{m}\left(P_{A}, 0\right)$ : If free trade were expected ex ante, no labor would allocate itself to the import competing sector. If in fact $r_{m}=r_{x}$,

$$
\imath \frac{\lambda(\not /-1)+P_{A}(\ell, t)+1}{P_{A}(\ell, t)+1}=1+t
$$

Let $t^{\circ}$ solve this equation for $\ell=1$. Then, when the forecast value of $t$ falls at least to $t^{\circ}$, labor will allocate itself fully to the comparative advantage sector. I assume that, at this point, $\Delta r_{m}$ receives zero weight in the government's objective function: Multilateral negotiations will deliver free trade.

Next, consider the responsiveness of the quasi-rents to the allocation of labor:

$$
\begin{gathered}
\frac{\ell}{\gamma_{s}} \frac{\partial r_{x}}{\partial \ell}=1 / \frac{P_{A}-1-\pi(\beta-1)}{P_{A}+1+\pi(\beta-1)}\left(\frac{\ell}{P_{A}} \frac{d P_{A}}{d \ell}\right) \\
\frac{\ell}{\gamma_{m}} \frac{\partial r_{m}}{\partial \ell}=1 / 2 \frac{P_{A}-1}{P_{A}+1}\left(\frac{\ell}{P_{A}} \frac{d P_{A}}{d \ell}\right) .
\end{gathered}
$$

Now,

$$
\frac{d P_{\mathrm{A}}}{d \ell}=\frac{\partial P_{\mathrm{A}}}{\partial \ell}+\left(\frac{\partial P_{\mathrm{A}}}{\partial t}\right)\left(\frac{\partial t}{\partial t}\right)=\frac{\partial P_{\mathrm{A}}}{\partial \ell}+\left(\frac{\partial P_{\mathrm{A}}}{\partial t}\right) t_{1}\left(-\frac{\partial \tau^{\alpha+}}{\partial \ell}\right)
$$

This expression is positive, by the definition of $P_{A}(\ell, t)$ and by Proposition 2 . Thus $r_{m}$ and $r_{x}$ will be positively related to $\ell$ and $r_{x}$ will increase proportionally less in response to a rise in $\ell$ than will $r_{m}$, so, in a neighborhood of $r_{m}=r_{x}, \frac{\partial r_{x}}{\partial \ell}<\frac{\partial r_{m}}{\partial \ell}$. This ensures stability of the process whereby labor allocates itself between sectors, in response to the rational forecast of $t$, to equilibrate the quasi-rents. 
Proposition 3 Suppose that $\mathrm{t}$, the common tariff expected to prevail after this period's negotiations are complete, is greater than $\mathrm{t}^{\circ}$. Then the equilibrium allocation of labor will be determined by (7).

Next, I investigate the implications for resource allocation of a common rate of tariff reduction. Implicit differentiation of (7) yields

$$
\frac{d \ell}{d t}=\frac{\frac{\left(P_{A}(\ell, t)+1\right)^{2}}{\alpha \pi(\beta-1)}-\frac{\partial P_{A}}{\partial t}}{\frac{\partial P_{A}}{\partial \ell}}<0
$$

by definition of $P_{A}(\ell, \mathrm{t})$.

Geometrically, the expectation of liberalization in the negotiations to come shifts the $e x$ ante $r_{m}$ schedule down and the ex ante $r_{x}$ schedule up, implying that the equilibrium $\ell$ rises. When the expected tariff falls as low as $t^{\circ}$, it instantaneously falls to zero. All labor allocates itself to the comparative advantage sector.

The theory of gradual multilateral liberalization developed in this section can be interpreted as based upon time inconsistency. Labor allocates itself to the comparative-disadvantage sector because it knows that, once it is allocated there, the government will not negotiate protection away. Could the government credibly commit to free trade, no labor would enter the comparative-disadvantage sector. Thus there would exist no interest opposed to free trade. Staiger and Tabellini (1987) provide a related analysis.

\section{Unilateralism}

The rate of multilateral tariff reduction is limited to the lowest reduction any country would prefer ex post. Perhaps, as Bagwell and Staiger (1990) argued in another context, a system of unilateralism can improve on this. Would such a system be developed and used? What would it look like? The following subsection argues intuitively what properties such a system should have to produce affirmative answers, and this is followed by a formal analysis. 


\section{The potential for unilateralism}

Suppose countries establish, before some negotiating round, a rule stipulating circumstances under which, after the completion of negotiations and after the revelation of which goods and countries are the technological leaders, protection might be granted to beleaguered import-competing interests. Since the purpose is to preserve, at least partly, an outcome for special interests in the face of unanticipated developments, they should be either quantitative or sufficiently nimble in execution that it does not matter whether they are quantitative (i.e., TARIFF-QUOTA EQUIVALENCE).

The countries that turn out to be laggards could ex post apply such a rule. Would they wish to do so? Clearly they would not if they were confident that this would prompt retaliation: This would be a roll-back of the negotiated tariff reductions which are already less than what the laggards want ex post. So, would the leaders retaliate? Such a roll-back would move the common tariff reduction even further from what the leaders would want. Still, if the laggards unilaterally increase protection, the leaders are likely to retaliate. Unilateral protection would be concession reneging: Since the leaders do not receive all the market access they had bargained for, they will not want to grant all the access they have promised. If everyone realizes the leaders will retaliate, such a rule would be of no value. It would be neither instituted nor used, unless the rule eliminates the motive to retaliate.

To make concession reneging acceptable, the rule could COMPENSATE the leaders. They need not be fully compensated, just enough so that they do not forsake the compensation by retaliating instead. Allowing them the trade rents generated by the unilateral measures would contribute to this. There may be a second source of compensation as well: a greater common tariff reduction, if unilateralism allows that to be negotiated.

To see when that might happen, consider the followers. They end up competing, at a disadvantage, with the leaders in the import markets of the laggards. The rents associated with unilateral protection would be worth much less to the followers, with no cost reductions, than to the leaders. Also, they would not gain from any increase in tariff reduction. So prospects are dim that these countries would be compensated enough to forestall retaliation. More important, since the followers' preferences determine the rate of common tariff reduction, no increase would in fact take place; indeed, that rate may well decrease. Thus the whole case for unilateralism will unravel unless the interests of the followers are addressed. For this reason, the unilateral measures should be DISCRIMINATORY. If they apply to the leaders but not to the followers, the latter would have nothing to retaliate against. The unilateral measures would instead enhance the ability of the followers to compete in the markets of the laggards. Consequently they would now prefer a greater common rate of tariff reduction: The negotiated tariff reduction should increase. 
The above argument assigns leaders, followers, and laggards distinct roles in the exercise of unilateralism, but the identification of these countries is fixed only for the current period. Thus the unilateral measures should be TEMPORARY - for the rest of the current period only.

Hypothesis Multilateralism may induce the introduction of tools of temporary unilateral protection that are quantitative, discriminatory, and give compensation to restrained exporters. Such an introduction might accelerate the rate of multilateral tariff reduction.

Note that four of the five stylized facts of unilateralism have been utilized. I now turn to a formal analysis.

\section{A model of unilateralism}

I now model unilateralism as a rule allowing laggard countries, after the realization of the technology draw, to apply temporary (i.e., for the rest of the current period only) quantitative restraints on imports from the leaders, allowing the latter the resulting trade rents. Let $\rho$ denote the (randomly selected) fraction of the leaders whose imports will be restrained by all laggards. I treat $\rho$ as exogenous and use it to index the breadth of unilateralism. Restrained leaders can export only $X_{R L}=\delta X_{F}+(1-\delta) X_{U L}$, where $X_{F}$ denotes the volume exported by followers and $X_{U L}$ that exported by unrestrained leaders. The parameter $\delta(0 \leq \delta \leq 1)$, also exogenous, will index the intensity of unilateralism. This model reflects the properties both argued for in the previous subsection and described in Section II.

Suppose the leaders have a comparative advantage in $A$. Then, with the assumed tastes, followers will be in equilibrium when:

$$
Q\left(B+\frac{X_{I}}{P_{S}}\right)=A-X_{P}
$$

Equilibrium for the unrestrained leaders requires:

$$
Q\left(B+\frac{X_{L Z}}{P_{.4}}\right)=A_{Z}-X_{U Z}
$$

where $X_{U L}$ denotes exports of the unrestrained leaders and $A_{L}$ productions by the leaders of $\operatorname{good} A$. For the restrained leaders: 


$$
Q_{A}^{R \perp}\left(B+\frac{X_{K \perp}}{P_{A}}\right)=A_{\perp}-X_{K \perp}
$$

where $\mathrm{Q}_{A}^{R L}$ denotes the relative domestic price of imports for the restrained leaders. From (9) and (10), $X_{U L}>X_{R L}$, which implies that $Q_{A}^{R L}>Q_{A}$. $X$ denotes the average level of $A$ exports:

$$
X=(1-\pi) X_{F}+\rho \pi X_{R L}+(1-\rho) \pi X_{U L}=[1-\pi(1-\rho \delta)] X_{F}+\pi(1-\rho \delta) X_{U L}
$$

Finally, for the laggards,

$$
Q_{*}^{* *}\left(B^{* *}-\frac{X}{P_{G}}\right)=A^{*+}+X
$$

Now, (8) and (9) imply

$$
Q\left(B+\frac{X}{P}\right)=\widetilde{A}-X
$$

where $\quad \widetilde{A}=[1-\pi(1-\rho \delta)] A+\pi(1-\rho \delta) A_{I^{\prime}} . \quad$ From this and the above,

$$
P_{s, k}(\ell, \mathrm{\rho}, \delta)=\frac{\widetilde{A}+(1+t) A^{*}}{B^{*}+(1+t) B}
$$

so that $\frac{\partial P_{A}}{\partial \rho}, \frac{\partial Q_{A}}{\partial \rho}, \frac{\partial P_{A}}{\partial \delta}, \frac{\partial Q_{A}}{\partial \delta}<0$.

Also,

$$
X=\frac{\widetilde{A} B^{*}+(1+t)^{2} A^{*} B}{(2+t)\left[B^{*}+(1+t) B\right]}
$$

Furthermore, (8) and (9) imply:

$$
X_{L E}-X_{F}=\frac{A_{I}-A}{2+t}
$$


while (8) and (10) give:

$$
Q_{A}^{R \perp}=Q_{N} \frac{A_{\perp}-X_{R \perp}}{\widehat{A}-X_{R \perp}}
$$

where $\hat{A}=\delta A+(1-\delta) A_{L}$.

\section{The followers}

Suppose that the breadth $\rho$ of unilateralism is raised above zero, with $\delta$ fixed at some positive level. I now investigate whether, as expected, this will improve the fate of the countries that turn out to be followers by reducing competition in their export markets from the leaders. For a given common tariff $t$ and rate of tariff reduction $\tau$ the value of the objective function of each follower government will be:

$$
\phi(\tau)=\frac{\alpha \alpha}{2} Q_{4}^{1 / 2} \tau-\left(\frac{\alpha}{2} Q_{4}^{1 / 4} \tau\right)^{1+\gamma}
$$

Each government, realizing its country is small, takes $P_{A}$ as independent of its own actions, but this common value will be affected by the increase in $\rho$. Consider the marginal effect on the $\phi$ of each follower government of increasing $\rho$ after $\tau$ has been implemented.

$$
\left.\frac{\partial \phi^{F}}{\partial \rho}\right|_{\tau}=-\frac{\frac{\rho}{Q_{A}} \frac{\partial Q_{A}}{\partial \rho}}{2 \rho}\left[\frac{\alpha a}{2} \frac{1}{Q_{A}^{1 / 2}}+(1+\gamma)\left(\frac{\alpha}{2} Q_{A}^{1 / 1}\right)^{1+\gamma} \frac{1}{\tau}\right]
$$

Then, since $\frac{\partial Q_{s}}{\partial \rho}<0$, an increase in $\rho$ will always raise the $\phi$ of each follower government, at any $\tau$. So these governments would welcome the exercise of unilateralism, and they would prefer its breadth to be comprehensive $(\rho=1)$ and its intensity complete $(\delta=1)$. Furthermore, it follows from (5) that $\frac{\partial \tau^{\alpha}}{\partial \rho}>0, \frac{\partial \tau^{\alpha+}}{\partial \delta}>0$, implying that a system of unilateralism will 
cause the negotiated liberalization rate to increase and that the increase will be greater the greater the breadth and intensity of unilateralism.

Proposition 4 If unilateralism without retaliation is introduced, the negotiated rate of liberalization will increase, the governments of the countries that turn out to be followers will be better off, and these governments would wish unilateralism to be comprehensive and complete (which would also maximize the rate of liberalization).

\section{The unrestrained leaders}

I next investigate whether, as expected, the increase in $\rho$ would benefit unrestrained leaders. Again, there are no surprises. For a given common $t$ and rate of tariff reduction $\tau$ the value of the objective function of each unrestrained leader government will be

$$
\phi^{u l}=\frac{\beta \alpha a}{2} Q_{H}^{-1 / 2} \tau-\left(\frac{\alpha}{2} Q_{\mu}^{1 / 4} \tau\right)^{1+\gamma}
$$

So,

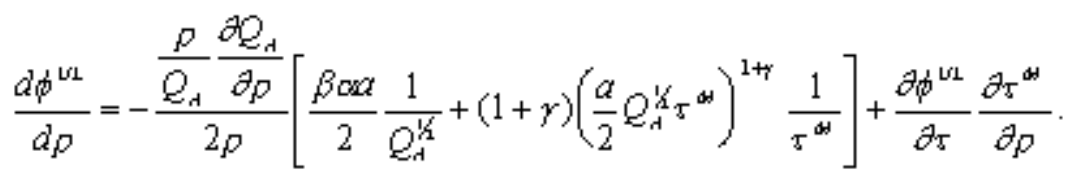

The first term on the right-hand side of (13), which I call the protective effect, measures the gain to each unrestrained leader from decreased competition in export markets; this is similar to the right-hand side of (12) but larger, since $\beta>1$. The second term, the liberalizing effect, measures the effect on unrestrained leaders of the change in the negotiated tariff reduction implied by the increase in $\rho$. Since the negotiated rate of tariff reduction is always less than what the unrestrained leaders wish ex post, $\partial \phi^{U L} / \partial \tau>0$, and the previous subsection showed that $\partial \tau^{M} / \partial \rho>0$. Thus an increase in $\rho$ will raise the $\phi$ of each unrestrained leader government via both effects. It would welcome unilateralism, and also prefers to be the only unrestrained leader (that is, that $\rho=(n-1) / n)$, and to have the intensity of unilateralism complete.

Proposition 5 If unilateralism without retaliation is introduced, the governments of the unrestrained leaders will be better off, and these governments will wish complete intensity and as few other unrestrained leaders as possible. 


\section{The restrained leaders}

The national income of restrained leaders, at domestic prices, equals:

$$
Q_{A}^{R L}\left(B+\frac{X_{F}}{P_{A}}\right)+A_{1}-X_{F}=\left(A_{\perp}+Q_{A}^{R L} B\right)+\left(t X_{F}\right)+\left(\frac{Q_{A}^{R L}-Q_{A}}{P_{A}} X_{F}\right)
$$

The first term on the right is the value of production, paid to the workers as wages. The second term equals total tariff revenue, distributed in lump-sum fashion. The third term, which I denote below by $R^{R L}$, is the rent generated by the restraints, and I assume that this accrues to the export sector. Then the ex-post reward of labor employed in the export sector of the restrained leaders is:

$$
\gamma_{x}^{R L}=\left(Q_{A}^{R L}\right)^{-1 / 2}\left[\frac{A_{1}}{\ell}+\frac{R^{R L}}{\ell}\right]
$$

and labor in the import-competing sector will earn:

$$
\gamma_{\mathrm{m}}^{R L}=a\left(Q_{\mathrm{r}}^{R L}\right)^{1 / 1}
$$

After some manipulation, (14) and (16) yield:

$$
\frac{1+t}{r_{x}^{R L}} \frac{d r_{x}^{R L}}{d t}=-\frac{1}{2}\left(\frac{1+t}{Q_{d}^{R L}} \frac{d Q_{t}^{R L}}{d t}\right)+\frac{R^{R L}}{A_{\perp}+R^{R L}}\left(\frac{1+t}{R^{R L}} \frac{d R^{R L}}{d t}\right)<0
$$

and

$$
\frac{1+t}{\gamma_{m}^{K L}} \frac{d r_{m}^{K \perp}}{d t}=\frac{1}{2}\left(\frac{1+t}{Q_{t}^{K \perp}} \frac{d Q_{d}^{F \perp}}{d t}\right)>0
$$

Suppose that initially $\delta=0$, with $\rho$ set at some arbitrary positive value: Unilateralism has no intensity. So the objective function of restrained leaders initially equals that of unrestrained leaders: $\phi^{R L}=\phi^{U L}$. Then consider the effect of $d \delta>0$ on the restrained leaders; denote this 
increment, in the absence of retaliation, by $\frac{\partial \phi^{E L}}{\partial \delta}$. I assume that, should these (now effectively) restrained leaders retaliate, the laggards convert their unilateral measures into conventional (nondiscriminatory) tariffs, allowing themselves to appropriate $R^{R L}$, that is, unilateralism plus retaliation is equivalent ${ }^{10}$ to a reduction in the rate of liberalization $\tau$. The

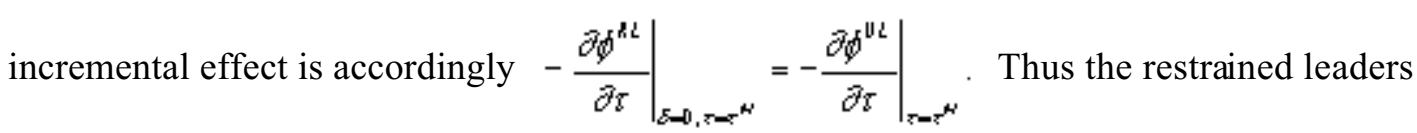
will find retaliation tempting only if

$$
\left.\frac{\partial \phi^{r 1}}{\partial \delta}\right|_{z=0}<-\left.\frac{\partial \phi^{L 1}}{\partial \tau}\right|_{c=c^{*}}
$$

Now

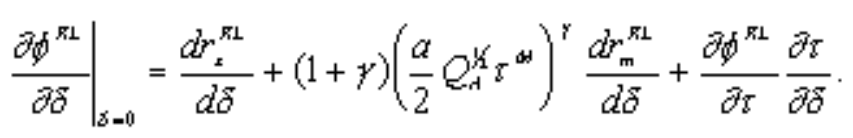

The effect of a marginal restraint on the return to labor in the export sector is:

$$
\left.\frac{d r_{y}^{n L}}{d \delta}\right|_{\delta=0}=-\left.\frac{1}{2} \frac{r_{x}^{n}}{Q_{n}} \frac{\partial E_{-\pi}^{n L}}{\partial \delta}\right|_{\delta-1}+\left.Q_{-\pi}^{-1 / 2} \frac{1}{2} \frac{\partial R^{n L}}{\partial \delta}\right|_{\delta-1} .
$$

The first term on the right is the direct effect of the export restriction and the second term is the compensating emergence of trade rent. From (11),

$$
\left.\frac{\partial Q_{n}^{n L}}{\partial \delta}\right|_{\delta=0}=Q_{-1} \frac{A_{L}-A}{A_{L}-X_{U L}}+\frac{\partial Q_{n}}{\partial \delta}
$$

and from the definition of $R^{R L}$,

\footnotetext{
${ }^{10}$ Alternatively, the laggards might convert their unilateral measures into conventional tariffs that apply only to the products of the restrained leaders, i.e., that discriminate. But I will not consider this possibility as it would presumably make retaliation even more likely.
} 


$$
\left.\frac{\partial R^{n L}}{\partial \delta}\right|_{\delta=0}=\left[\left.\frac{\partial Q_{n}^{n L}}{\partial \delta}\right|_{\delta=0}-\frac{\partial Q_{n}}{\partial \delta}\right] \frac{X_{U L}}{P}=(1+t) X_{U L} \frac{A_{L}-A}{A_{L}-X_{U L}}>0
$$

Then the net effect on the real reward of labor in the export sector reduces to:

$$
\left.\frac{\partial r_{\nu}^{I}}{\partial \delta}\right|_{\delta-0}=\frac{A_{L}-A}{A_{L}-X_{U L}} \frac{Q_{H}^{-1 / 2}}{\ell}\left[(1+t) X_{U L}-\frac{1}{2} A_{L}\right]
$$

This will be positive if the term in brackets is positive: a large enough initial export position will generate enough rent to compensate fully for the restrictions. Next, the effect on labor in the import-competing sector reduces to:

$$
\left.\frac{\partial r_{m s}^{k}}{\partial \delta}\right|_{s=0}=\frac{1}{2} r_{m}^{k} \frac{A_{L}-A}{A_{L}-X_{U U}}\left[\frac{(1-\pi) A+\pi(1-\rho) A_{L}+(1+t) A^{*}+\pi \rho X_{U L}}{(1-\pi) A+\pi A_{L}+(1+t) A^{*}}\right]>0 .
$$

So labor in the import-competing sector benefits from unilateralism at a sufficiently small intensity. The overall effect on the objective function of the negotiators of restrained leaders is then:

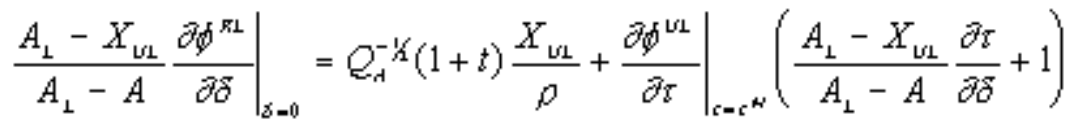

$$
\begin{aligned}
& +(2+\gamma)\left(\frac{a}{2} Q_{-d}^{1 / 1 / \tau^{\alpha+1}}\right)^{1+\gamma} \frac{1}{\tau^{\alpha+}} \frac{(1-\pi) A+\pi(1-p) A_{\perp}+(1+t) A^{*}+\pi p X_{\mathrm{LL}}}{(1-\pi) A+\pi A_{\perp}+(1+t) A^{*}}
\end{aligned}
$$

$>0$.

Each of the three terms on the right is positive. Thus, as long as $\delta$ is sufficiently small, leaders will not only not be tempted to retaliate, they will also perceive the exercise of unilateralism as beneficial, according to the government negotiators' objective function. 
Proposition 6 Unilateralism, at any breadth, will necessarily be perceived as beneficial by the governments of restrained leaders, if the intensity is small enough.

\section{The laggards}

The value of the laggards' negotiators' objective function is:

$$
\phi^{G}=1 / 2 r_{x}^{G} \tau^{M}-\left(1 / 2 r_{m}^{G} \tau^{M}\right)^{1+\gamma}
$$

But, since the laggards would potentially implement unilateralism, I now need to specify the objective function of the bureaucrats who would administer it. The fifth stylized fact of unilateralism (The restrictions are designed by officials distinct from those who negotiate international trade agreements) now becomes relevant. I accordingly allow administrators an objective function that, although of the same form as the negotiators' (1), has its own willingness to protect, $\mu$. Thus the value of the laggards' administrators' objective function is now:

$$
\phi_{A}^{\square}=1 / 2 r_{x}^{\square} z^{\alpha+}-\left(1 / 2 r_{m}^{\square} z^{\alpha+1}\right)^{1+\mu} \text {. }
$$

Perhaps the easiest way to assess the importance of allowing administrators a distinct objective function of their own is to suppose initially that they do not have one and deduce the implications. So I initially suppose that $\mu=\gamma$ and, therefore, $\phi_{A}^{G}=\phi^{G}$.

The total marginal effect on $\phi^{G}$ of raising $\rho$ above zero, assuming no retaliation, is

$$
\frac{d \phi^{\square}}{d \rho}=\frac{\partial \phi^{\square}}{\partial_{p}}+\frac{\partial \phi^{\sigma}}{\partial_{\tau}} \frac{d \tau^{\alpha+}}{d_{\rho}}
$$

where the first term on the right indicates the direct protective effect and the second the indirect liberalizing effect. Now, 


$$
\begin{aligned}
\frac{\partial \phi^{G}}{\partial p} & =\frac{\partial r_{x}^{G}}{\partial p}+(1+\mu)\left(\frac{\partial r_{m}^{G}}{\partial} \tau^{M}(1+t)\right)^{\mu} \frac{\partial r_{m}^{G}}{\partial p} \\
& =-\left[\frac{\partial r_{x}^{G}}{\partial t}(1+t)+(1+\mu)\left(\frac{\partial r_{m}^{G}}{\partial} \tau^{M}(1+t)\right)^{\mu} \frac{\partial r_{m}^{G}}{\partial t}(1+t)\right] \frac{1}{Q_{A}} \frac{\partial Q_{A}}{\partial p} \\
& =\frac{\partial \phi^{G}}{\partial \tau} \frac{1}{Q_{A}} \frac{\partial Q_{A}}{\partial p} .
\end{aligned}
$$

The negotiated liberalization rate $\tau^{M}$ is less than what the laggards' negotiators most prefer $e x$ post, if $\mu=\gamma$. Thus $\frac{\partial \phi^{G}}{\partial \tau}>0$, which implies that $\frac{\partial \phi^{G}}{\partial \rho}<0$. Since a higher rate of liberalization is perceived as beneficial, a change in the welfare of exporters must, on the margin, dominate the accompanying change in the welfare of import-competitors.

But the indirect liberalizing effect will be beneficial, again with $\mu=\gamma$. Thus unilateralism will on balance benefit the governments of laggards when the latter effect dominates, which will be so when

$$
\frac{d \beta^{G}}{d, O}=\left[\frac{\partial \gamma^{M}}{\partial_{O}}+\frac{1}{Q_{A}} \frac{\partial_{A}}{\partial O}\right] \frac{\partial \partial^{G}}{\partial T}>0
$$

which, in turn, will hold if and only if

$$
\tau^{N}>\frac{1}{1 / \mu+1 / 2}
$$

The right-hand side is strictly increasing in $\mu$ and $\tau^{M}$ decreases in $\gamma$, ranging from infinity to zero. Thus, with $\mu$ constrained equal to $\gamma$, there exists a unique $\gamma^{\circ}$ with the property that unilateralism confers a net benefit on the laggards if and only if $\gamma<\gamma^{\circ}$.

But this is not all. Suppose that $\gamma>\gamma^{\circ}$ and that governments commit themselves to practice unilateralism should they become laggards. Whenever a country is a laggard it then shoots itself in the foot, but this benefits all non-laggard countries, raising the rate of liberalization. If $\gamma$ is sufficiently close to $\gamma^{\circ}$, the loss when a laggard will be dominated by the gain when not a laggard, so that, ex ante, every country is better off. 
Proposition 7 If $\mu=\gamma$ is not sufficiently greater than $\gamma^{\circ}$, all countries can benefit $\mathrm{ex}$ ante, according to the objective function (1), if each country adopts unilateralism at some intensity. This will raise the rate of liberalization.

\section{The effect of unilateralism on resource allocation}

The above examined the effect of unilateralism for a given pattern of resource allocation $\ell$. But if unilateralism exists, forward-looking labor will take that into account when deciding where to locate. With a system of unilateralism in place, the real ex-post quasi-rents become as follows, for a country with a comparative advantage in $A$ :

$$
\begin{aligned}
& r_{x}^{U R I}=\frac{\beta \alpha a}{Q_{A}^{1 / 2}} \quad r_{x}^{D L}=\frac{\beta \alpha a}{\left(Q_{A}^{R L}\right)^{1 / 2}} \quad r_{x}^{F}=\frac{\alpha a}{Q_{A}^{1 / 2}} \quad r_{x}^{G}=\frac{\alpha a}{Q_{B}^{1 / 2}} \\
& r_{m}^{U R L}=a Q_{A}^{1 / 2} \quad r_{m}^{R I}=a\left(Q_{A}^{R I}\right)^{1 / 2} \quad r_{m}^{F}=a Q_{A}^{1 / 2} \quad r_{m}^{G}=a Q_{B}^{1 / 2}
\end{aligned}
$$

and the expected returns accordingly become

$$
r_{i}(\ell ; t, \rho, \delta)=\frac{(1-\rho) \pi}{2} r_{i}^{U R I}+\frac{\rho \pi}{2} r_{i}^{R I}+\frac{1-\pi}{2} r_{i}^{F}+\frac{1}{2} r_{i}^{G}
$$

for $i=x, m$. Here $t$ denotes the common tariff rate expected (correctly) to prevail after the current round of negotiations - that is, $t=t_{1}-\tau^{M}\left(1+t_{1}\right)$, where $t_{1}$ denotes the tariff inherited from the previous period - and $\rho$ and $\delta$ denote the parameters of the system of unilateralism that is in place or expected (correctly) to be put in place. Given the values of these policy variables, the allocation of resources is determined by

$$
r_{x}(\ell ; t, \rho, \delta)=r_{m}(\ell ; t, \rho, \delta)
$$

Differentiate this expression implicitly to determine the effect of an increase in the intensity of unilateralism on the ex-ante allocation of resources. 


$$
\frac{d \ell}{d \delta}=\frac{\left[\frac{\partial r_{x}}{\partial \delta}-\frac{\partial r_{m}}{\partial \delta}\right]}{\frac{\partial r_{m}}{\partial 2}-\frac{\partial r_{x}}{\partial \ell}}+\frac{\left[\frac{\partial r_{x}}{\partial t}-\frac{\partial r_{m}}{\partial t}\right]}{\frac{\partial r_{m}}{\partial \ell}-\frac{\partial r_{x}}{\partial \ell}} t_{1} \frac{\partial \tau}{\partial \delta}
$$

The first term on the right is the direct effect of unilateralism on resource allocation, and the second term is the indirect effect due to the fact that the existence of unilateralism will alter the liberalization expected (correctly) to be negotiated. Consider a differential increase of $\delta$ above zero, that is, the introduction of unilateralism at an arbitrarily low intensity. Then the discussion in Section IV establishes that the denominators and the first bracketed term in the numerator of the second term on the right are each positive, and Proposition 7 establishes that $\partial \tau / \partial \delta>0$. Thus the indirect effect is positive. So consider the numerator of the first term on the right, the direct effect.

$$
\begin{aligned}
\frac{\partial r_{x}}{\partial \delta}-\frac{\partial r_{m}}{\partial \delta} & =\frac{\rho \pi}{2}\left[\frac{\partial r_{x}^{D L}}{\partial \delta}-\frac{\partial r_{m}^{R L}}{\partial \delta}\right]+ \\
& \left(-\frac{\partial Q_{A}}{\partial \delta}\right) \frac{a}{4} Q_{A}^{-1 / 2}\left\{\alpha[(\beta-1) \pi(1-\rho)+(1-\rho \pi)] Q_{A}-\frac{\alpha}{1+t}+(1-\rho)-\frac{1+t}{Q_{A}}\right\}
\end{aligned}
$$

Since $Q_{A}>1$ and $\partial Q_{A} / \partial \delta<0$, a sufficiently small value of $\rho$ will guarantee that this term is positive: The direct effect of unilateralism, as well as the indirect effect, will be to reallocate resources toward the comparative advantage sector.

Proposition 8 The introduction of unilateralism at a sufficiently small intensity and breadth will induce an increased allocation of labor to the comparative advantage sectors.

\section{The in surance triangle}

Note two curious features of how unilateralism functions. First, unilateralism is appealing to governments if their willingness to protect $(\gamma)$ is low, not high. This is because a lower willingness to protect produces a greater beneficial liberalizing effect.

Second, unilateralism functions as a form of insurance. But, unlike the literature on tariffsas-insurance [Eaton and Grossman (1985), Dixit (1987, 1989)] the role for insurance is itself 
a product of a positive willingness to protect, and its value is not that a laggard government itself have something to fall back on (ex post such a government would prefer not to implement it - see below) but rather that its effect on others allows all to negotiate a greater rate of liberalization. ${ }^{11}$ Countries know that, should they turn out to be followers (the most reluctant liberalizers), their interests will be safeguarded by the efforts of the laggards to protect their own import-competing interests, and that these efforts will be acceptable to the leaders. ${ }^{12}$ This can not be appreciated in a two-country model. The insurance functions through a subtle interplay between all three groups: the insurance triangle.

If this is how unilateralism works, could it not take the form of export subsidies by followers, either instead of or along with, import protection by laggards? An answer will emerge below.

\section{The split personality}

The analysis thus far in this section, culminating in Propositions 7 and 8, has focused on the possibility that multilateralism might imply a role for unilateralism: Causation has been from the former to the latter. But unilateralism, to be effective, also requires a multilateral component. This is because Proposition 7, by itself, does not get us far enough. The reason, in part, is time consistency.

Unilateralism will be effective only if countries choose to implement it when they become laggards. They benefit only when the beneficial indirect liberalizing effect dominates the harmful protective effect. But the former will be past history when the laggards decide whether to implement unilateralism. Thus the laggard governments, according to the negotiators' objective function, will decline to implement unilateralism ex post.

This time-consistency problem is compounded — and this is absolutely essential — by an externality. Governments with the objective function (1) would like, if $\gamma<\gamma^{\circ}$, to convince each other that they will practice unilateralism when they turn out to be laggards, because this would produce a higher rate of tariff reduction, to the ex ante benefit of all. But all know that, ex post, the government of a laggard with the objective function (1) would not implement unilateralism. What if governments can precommit to implement unilateralism should they become laggards? Because the time consistency problem is compounded by an externality, no government would undertake such a pre-commitment unilaterally: The beneficial liberalizing effect depends on a general adoption of unilateralism.

\footnotetext{
${ }^{11}$ There is a (very rough) analogy here with the role for trade adjustment assistance advanced by Fung and Staiger (1996).

${ }^{12}$ Thus, in the early 1980s, the US automobile industry (laggards) acquired protection acceptable to the Japanese industry (leaders) and beneficial to the Europeans and Koreans (followers).
} 
Proposition 9 The introduction of unilateralism (raising $\rho$ above zero) will have no effect, if implemented by authorities who have discretion and who set $\mu=\gamma$, because they will always decline ex post to implement it. Furthermore, no government negotiator with $\mu=\gamma$ would be willing unilaterally to delegate authority to implement unilateralism ex post to some other agent.

There are two potential ways around this problem, and both require a multilateral component to unilateralism. The first is simply to internalize the externality by having the countries jointly adopt binding unilateralism. That is, the latter could itself be the product of multilateral negotiation. (Or they might jointly bind themselves to subsidize exports whenever they turn out to be followers).

But this does not correspond to reality: The fifth stylized fact of unilateralism (The restrictions are designed by officials distinct from those who negotiate international trade agreements) is at variance with this possibility. So consider instead the consequences of countries individually adopting unilateralism systems with $\mu \neq \gamma$. Let $\tau_{A}^{G}(\mu)$ denote the rate of liberalization that is optimal, ex post, for administrators with a willingness to protect of $\mu$, in a country that turns out to be a laggard.

Define $\mu(\gamma)$ to be the solution to

$$
\tau^{\mathrm{C}}(\mu(\gamma))=\tau^{\mathrm{H}}(\gamma) \text {. }
$$

Propositions 1 and 2 imply that $\mu(\gamma)>\gamma$. Further, Proposition 2 implies that, if $\mu \geq \mu(\gamma)$, the negotiated rate of liberalization will be no less than what the laggard administrators most prefer ex post. Thus, from (17), $\frac{\partial \phi_{A}^{\square}}{\partial_{T}}<0$, whence $\frac{\partial_{\phi} \phi_{A}^{5}}{\partial_{p}}>0$. Therefore the administrators will indeed implement unilateralism when their countries turn out to be laggards: The time consistency problem disappears.

Proposition 10 If $\mu \geq \mu(\gamma)>\gamma$ laggards will implement unilateralism and, at some intensity, this will benefit all other countries; if $\gamma$ is sufficiently small this will also benefit the laggards, according to the objective function (1).

Four comments are in order. First, for unilateralism to work, the willingness to protect of the administrators must not merely marginally exceed that of the negotiators, it must significantly exceed the latter. Second, this is not an example of individual countries strengthening the bargaining positions of their negotiators by pre-committing to ex post action. The benefit of unilateralism to an individual country comes from the assurance that all other countries will practice it when they are laggards. Regardless of how forward-looking they may be, the negotiators of NO country will wish their own country to adopt such a system of unilateralism. The fifth stylized fact of unilateralism (The restrictions are designed by officials distinct 
from those who negotiate international trade agreements) is absolutely critical here. Third, the higher rate of liberalization will be perceived as undesirable by the administrators, and, if $\mu$ is significantly great, this undesirable indirect effect from introducing a small $\rho$ will necessarily overwhelm the direct protective effect: Unilateralism will be on the whole undesirable from the administrators' point of view. But this has no effect on feasibility, because the liberalizing effect will be past history when the administrators are called upon to act. That is, such unilateralism will be time consistent. Fourth, with unilateralism in place there is no longer a possibility of subsidizing the exports of followers, since any such subsidies would be neutralized by the laggards..$^{13}$

\section{The compatibility problem}

But, if the restrictions must be designed by officials distinct from those who negotiate international trade agreements, can we be assured that the systems of unilateralism they adopt will possess the desired properties (i.e., the other stylized facts)? Since these officials would prefer unilateralism without complete retaliation rather than with it, and since Propositions 4, 5 and 6 continue to apply, the logic of this section, offering an explanation for those stylized facts, also continues to apply: The desired properties should be there. But there is no reason to think that either the breadth, $\rho$, or the intensity, $\delta$, of the unilateralism the officials provide will be desirable from the negotiators' point of view.

This is the compatibility problem: If unilateralism is not a deliberate multilateral creation (and in fact it is not) then it can be useful to the negotiators only if imposed by officials whose objectives are significantly at odds with those of the negotiators.

Once systems become common, they could be perceived as of potential benefit by government negotiators meeting together, even though no negotiator would have been willing to adopt such a system individually. But an immediate implication of the compatibility problem (also in accord with actual experience) is that these negotiators have an incentive to expand multilateral negotiations to address the conduct of unilateralism.

Proposition 11 Government negotiators will, together, have an incentive to accept unilateralism but also to include codes of conduct for it in their multilateral negotiations.

\footnotetext{
${ }^{13}$ Countervailing duties, of course, do just that.
} 


\section{Concluding Remarks}

I've argued that unilateralism and multilateralism comprise a coherent international commercial system. I've reduced each of these to a few basic principles, and discussed how they relate to each other. The essential argument follows.

- Multilaterally negotiated tariff reduction is limited by the smallest reduction any country will want ex post: that most advantageous to those countries who compete with the exports of the technological leaders.

- This pace can be accelerated, and the allocation of resources to the comparative advantage sectors can be increased, if those countries that import the exports of the technological leaders make universal use of temporary, quantitative, discriminatory protection compensating restricted exporters.

- Such unilateralism works by conferring a form of social insurance resulting from a subtle interplay between three distinct sets of countries: the insurance triangle.

- The use of such a system is constrained by a time consistency problem compounded by an externality.

- With unilateralism adopted by countries individually rather than collectively, to be useful it must be designed by officials significantly more willing to protect than are the negotiators themselves, who would be unwilling to delegate such authority: Trade policy needs its "split personality."

- This compatibility problem implies an incentive to address multilaterally the conduct of unilateralism.

This theory of unilateralism depends critically on the existence of a multilateral world. The key concepts - the insurance triangle, time-consistency compounded by an externality, the necessity of a split personality, the compatibility problem - cannot be understood at all in a two-country environment.

The process of multilateral trade liberalization generates a potential motive for protectionist policy tools with exactly those properties that I have argued do in fact constitute contemporary unilateralism. This in turn requires - again in accord with actual experience - a multilateral component. It all fits together. 


\section{References}

Bagwell, K. and R. W. Staiger (1990), “A Theory of Managed Trade,” American EcoNOMIC REviEW 80, 779-795.

Bagwell, K. and R. W. Staiger (1999a), “An Economic Theory of GATT,” AME Rican Econo mic Review 89 (1), March, 215-248.

Bagwell, K. and R. W. Staiger (1999b), "Multilateral Trade Negotiations, Bilateral Opportunism and the Rules of GATT," Working Paper, Department of Economics, University of Wisconsin.

Baldwin, R. E. and J. W. Steagall (1994), "An Analysis of US International Trade Commission Decisions in Antidumping, Countervailing Duty and Safeguard Cases," CEPR Discussion Paper No. 990.

Corden, W. M. (1997). Trade Policy and Economic Welfare, 2 ${ }^{\mathrm{ND}}$ ed. (Oxford: Oxford University Press).

Dixit, A. (1987), “Trade and Insurance with Moral Hazard," Journal of International EсоNomics 23 (3/4), November, 201-220.

Dixit, A. (1989), “Trade and Insurance with Adverse Selection," Review of Econo MIC STUdies 56 (2), April, 235-247.

Eaton, J. and G. M. Grossman (1985), "Tariffs as Insurance: Optimal Commercial Policy When Domestic Markets Are Incomplete," Canadian Journal of Economics 18(2), May, 258-272.

Ethier, W. J. (1991a), “The Economics and Political Economy of Managed Trade.” In: A. L. Hillman (ed.), Markets and Politicians, (Boston: Kluwer Academic Publishers), 283-306.

Ethier, W. J. (1991b), "Voluntary Export Restraints.” In: A. Takayama, M. Ohyama and H.

Ohta (eds.), Trade, Policy, and International Adjustments, (San Diego: Academic Press), 3-18.

Ethier, W. J. (1993), “An Antidumping Law with a Distorted Home Market.” Chapter 17 in: H. Herberg and N. V. Long (eds.), Trade, Welfare, and Econo mic Policies, (Ann Arbor: University of Michigan Press), 279-97.

Ethier, W. J. (1994), "Protección discrecional en la economía mundial contemporánea (Discretionary Protection and the Contemporary World Economy)," CuAdernos ECONOMICOS DE ICE 57 (2), 231-242.

Ethier, W. J. (1998a), “The New Regionalism,” Econo mic Journal 108 (449), July, 1149-1161.

Ethier, W. J. (1998b), "Reciprocity, Nondiscrimination, and A Multilateral World," Working Paper, Department of Economics, University of Pennsylvania, October. 
Ethier, W. J. (1998c), "Regionalism in A Multilateral World,"Journal of Political

Eсомому 6 (106), December 1998, 1214-1245.

Ethier, W. J. (1998d), “The International Commercial System,” EsSAys IN INTERNATIONAL

Finance No. 210, September 1998 (Princeton: Intemational Finance Section).

Ethier, W. J. (2001), “Theoretical Problems in Negotiating Trade Liberalization,” European Journal of Political Economy, forthcoming.

Ethier, W. J. and H. Horn. "Results-Oriented Trade Policy," Review of International ECONOMICs 4(1), 1996, 17-39.

Fung, K. C. and R. W. Staiger (1996), "Trade Liberalization and Trade Adjustment Assistance." In Canzoneri, M., W. J. Ethier, and V. Grilli [eds.], The New Trans atlantiC Eсоnомy (Cambridge: Cambridge University Press), 265-286.

Harris, R. (1985), “Why Voluntary Export Restraints are 'Voluntary'," CanAdian JournaL of Economics 18, 799-809.

Hillman, A. L. (1982), "Declining Industries and Political-Support Protectionist Motives," American Economic Review 72, 1180-1190.

Hillman, A. L. (1990), "Protectionist Policies as the Regulation of International Industry," Public Choice 67, 101-110.

Kostecki, M. (1987), “Export-Restraint Arrangements and Trade Liberalization,” THE World ECONOMY 10, 442-450.

Krishna, K. (1989), “Trade Restrictions as Facilitating Practices,” Journal of International Economics 26, 251-270.

Prusa, T. J. (1992), "Why Are Antidumping Petitions Withdrawn?," Journal of InternaTional EConomics 33, 1-20.

Staiger, R. (1995), "International Rules and Institutions for Cooperative Trade Policy." Chapter 29 in Grossman, G. M. and K. Rogoff [eds.], Handbook of International EConomics, volume 3 (Amsterdam: Elsevier), 1495-1551.

Staiger, R. and G. Tabellini (1987), "Discretionary Trade Policy and Excessive Protection," American Economic Review 77, 823-828.

Tharakan, P. K. M. and J. Waelbroeck (1994), “Antidumping and Countervailing Duty Decisions in the E.C. and in the U.S.: An Experiment in Comparative Political Economy," European Economic Review 38, 171-193. 


\section{Appendix I: Instruments of Unilateralism}

Unilateralism consists of rules, or instruments, that may be explicit or implicit. This appendix describes several of the most important the instruments, and then describes how their nature and their application has been changing over time.

\section{The instruments}

I describe four prominent instruments.

Voluntary export restraints (VERs) ${ }^{14}$ fall outside both national laws and international agreements. The Uruguay Round made them more extralegal than ever. The following instruments, "administered protection," are provided for in many national laws and sanctioned by the WTO.

Antidumping duties. Dumping ${ }^{15}$ is pricing for export below either the cost of production or the price for comparable domestic sales. Antidumping laws provide a two-pronged investigation: determination of the dumping margin, if any; determination of material injury to domestic import-competing firms. If both determinations are positive, a temporary duty equal to the dumping margin is imposed on the good from the country whose firms have dumped. The national interest plays no role, and (in the US) the President cannot decline to impose the duty. These laws define certain behavior as objectionable and force import prices up when it occurs. Whether or not the behavior should be objectionable is beside the point: Arbitrary circumstances determine which import-competing interests may obtain temporary protection.

Countervailing duties apply to imports subsidized for export. Administration is similar to that of antidumping laws.

Safeguards provide ${ }^{16}$ temporary protection for domestic industries harmed by increased imports. Again, a material injury test is applied. But, in the US, the President may decline to impose a duty. More generally, duties imposed should be nondiscriminatory and should not increase protection overall: Duties should be reduced (in a nondiscriminatory way) on goods that are important exports of the exporting countries most affected by the safeguard measures.

\footnotetext{
${ }^{14}$ See Harris (1985), Kostecki (1987), Krishna (1989), and Ethier (1991a,b).

${ }^{15}$ See Ethier (1991b, 1992, 1993), Prusa (1992), Baldwin and Steagall (1994), and Tharakan and Waelbroeck (1994).
}

${ }^{16}$ See Ethier (1994). 
This list of four instruments excludes other tools, notably those for aggressive export expansion (e.g., Super 301 in the US). These are more characteristic of the US than of other countries. Also, I have analyzed these before (Ethier and Horn, 1996), and this paper concerns unilateralism as protection.

\section{Changing instrument use}

Use of these instruments has changed dramatically. First, usage has greatly increased since the 1960s. With the freedom to conduct traditional tariff policy progressively constrained by multilateral agreements, protectionist pressures have increasingly found outlets in the new protectionism.

Second, multilateral negotiation is broadening to encompass unilateral actions. The Tokyo Round established voluntary codes for the conduct of administered protection, and these were made mandatory for WTO members by the Uruguay Round. But, curiously, the code for safeguards has been loosened. Countries are now allowed, sometimes, to use them much as VERs have been used. The final outcome is far from clear.

Third, individual countries have continually changed their laws. These changes have generally reduced administrative discretion and made protection more likely.

Fourth, the mix among the instruments has changed dramatically, with the number of safeguard cases declining absolutely as well as relatively and the number of countervailing-duty and (especially) antidumping cases exploding.

\section{Appendix II: Prices}

\section{Relative commodity prices}

Recall that everyone spends half of his/her income on each good. Then, if $A, B, A^{*}$ and $B^{*}$ denote national production levels and $M$ each nation's trade in $B$,

$$
Q_{i}(B+M)=A-P_{i} M \quad \text { and } \quad Q_{i}^{*}\left(B^{*}-M\right)=A^{*}+P_{i} M
$$

These expressions can be rewritten: 


$$
P_{i}[1+t+1] M=A-P_{i}(1+t) B \quad \text { and } \quad P_{i}[1+1 /(1+t)] M=B^{*} P_{i} /(1+t)-A^{*}
$$

Thus

$$
A / P_{i}(2+t)-(1+t) B /(2+t)=M=B^{*} /(2+t)-(1+t) A^{*} /(2+t) P_{i} .
$$

These in turn imply:

$$
\begin{aligned}
& P_{i}=\left[A+(1+t) A^{*}\right] /\left[B^{*}+(1+t) B\right], \text { and } \\
& M=\left[A B^{*}-(1+t)^{2} A^{*} B\right] /(2+t)\left[A+(1+t) A^{*}\right] .
\end{aligned}
$$

$P_{i}$ will assume one of two alternative values, depending on which good is the technological leader. Since $A=[\pi \beta+(1-\pi)] \ell \alpha a, B=(1-\ell) a, A^{*}=(1-\ell) a$, and $B^{*}=\ell \alpha a$,

$$
P_{i}=P_{A}(\ell, t)=\pi[\beta-1] \frac{\alpha \ell}{\alpha \ell+(1+t)(1-\ell)}+1
$$

if $A$ is the leader, and $P_{i}=P_{B}=1 / P_{A}$ if $B$ is the leader. Then $P_{A}>1>P_{B}$.

\section{Real rewards}

The responsiveness of rents to the common tariff vector $t$ is:

$$
\begin{aligned}
& \frac{1+t}{r_{H}} \frac{\partial r_{\mu}}{\partial t}=-1 / 2\left\{1-\frac{1}{1+\frac{\alpha}{1+t} \frac{\ell}{1-\ell}} \frac{\left(P_{\mu}-1\right)}{P_{\mu}} \frac{\pi(\beta-1)-\left(P_{H}-1\right)}{P_{\mu t}+1+\pi(\beta-1)}\right\}<0 \\
& \frac{1+t}{r_{m}} \frac{\partial r_{m}}{\partial t}=1 / 2\left\{1-\frac{1}{1+\frac{\alpha}{1+t} \frac{\ell}{1-\ell}} \frac{\left(P_{\mu}-1\right)^{2}}{P_{\mu}\left(P_{s}-1\right)}\right\}>0 .
\end{aligned}
$$

These imply, when $r_{m}=r_{x}, \frac{\partial r_{x}}{\partial t}+\frac{\partial r_{m}}{\partial t}<0$ 